\title{
The Brexit vote and currency markets
}

\author{
Article
}

Accepted Version

Creative Commons: Attribution-Noncommercial-No Derivative Works 4.0

Dao, T. M., McGroarty, F. and Urquhart, A. (2019) The Brexit vote and currency markets. Journal of International Financial Markets, Institutions and Money, 59. pp. 153-164. ISSN 10424431 doi: https://doi.org/10.1016/j.intfin.2018.11.004 Available at https://centaur.reading.ac.uk/80864/

It is advisable to refer to the publisher's version if you intend to cite from the work. See Guidance on citing.

To link to this article DOI: http://dx.doi.org/10.1016/j.intfin.2018.11.004

Publisher: Elsevier

All outputs in CentAUR are protected by Intellectual Property Rights law, including copyright law. Copyright and IPR is retained by the creators or other copyright holders. Terms and conditions for use of this material are defined in the End User Agreement.

\section{www.reading.ac.uk/centaur}

\section{CentAUR}

Central Archive at the University of Reading

Reading's research outputs online 


\title{
The Brexit Vote and Currency Markets
}

\begin{abstract}
This paper studies the effect of the Brexit vote on the intraday correlation and volatility transmission among major currencies. We find that the vote causes an increase in the correlation among the safe-haven currencies of the Swiss franc and Japanese yen as well as gold, and also find a decrease in their correlation with the directly involved currencies of British sterling and the Euro. These changes are due to the appreciation of the former group and the depreciation of the latter group which represents a flight to quality of investors. We also observe a substantial decrease in volatility transmission between British sterling and the Euro following the Brexit vote due to lower levels of market integration. However the volatility transmission among the currencies has increased in general and their net spillover is positively correlated with their level of volatility and trading activities. Therefore we document the significant impact of the politically important Brexit vote on the high frequency correlation and volatility spillover in the foreign exchange market.
\end{abstract}




\section{Introduction}

The decision of the UK on June 24, 2016 to leave the EU is often referred to as the Brexit vote. This unique event is significant because this is the first time a member of the EU has voted to leave. In response to the vote, both the FTSE and other major international stock indices suffered negative returns. To be more specific, the FTSE 100, the Dow Jones Industrial Average and the DAX decreased by $3.2 \%, 3.4 \%$ and $6.8 \%$ respectively. In particular, banking stocks depreciated more substantially than they did when Lehman Brothers collapsed (Schiereck et al., 2016). Moreover, the vote has led to increased political and economic uncertainty since it remains to be seen what exit deal the UK will be able to negotiate with the EU (Ramiah et al., 2016). Motivated by the significance of the Brexit vote and the uncertainty after the vote, we study the effect of the Brexit vote on the intraday correlation and volatility transmission of major currencies to provide insights into investor behaviour and the resultant effect on the foreign exchange (FX) market.

The Brexit vote is an international event which will affect the global financial system, especially the FX market. This market is the largest in the world and the currencies directly involved in the vote, namely sterling and Euro, are two of the major currencies. According to the survey of the Bank of International Settlement (BIS) in 2016, the global foreign exchange market generates an average turnover of $\$ 5.1$ trillion on a daily basis. ${ }^{1}$ To truly grasp the incredible magnitude of this market, one can refer to the fact that the largest stock market in the world, namely the New York Stock Exchange (NYSE), is able to generate an average turnover of only $\$ 65.8$ billion per day, which is equal to just $1.3 \%$ of the typical level of trading activities in the currency market. ${ }^{2}$ The survey of the BIS also shows that the Euro and sterling are the second and fourth most traded currency respectively, accounting for $31.3 \%$ and $12.8 \%$ of the FX market turnover. As well as sterling and the Euro, we analyse other major currencies which are often considered safe-haven assets, namely the Swiss franc and Japanese yen (Angelo and Paul, 2010, De Bock and Filho, 2015, Grisse and Nitschka, 2015, Fatum and Yamamoto, 2016) as well as gold which has long been considered a safe-haven asset (Baur and Lucey, 2010, Baur and McDermott, 2010, Bredin et al., 2015).

\footnotetext{
${ }^{1}$ The survey is available at http://www.bis.org/publ/rpfx16fx.pdf

2 The NYSE trading statistics can be found at https://www.nyse.com/data/transactions-statistics-data-library
} 
Motivated by the importance of the Brexit vote and the literature on the effect of political and unique events on financial markets (e.g. Korkeamäki, 2011, Boutchkova et al., 2012, Pastor and Veronesi, 2012), we are the first to investigate the correlation and volatility transmission in the currency market after the vote. Our study is conducted in the high-frequency context which has received less attention than the daily and lower-frequency context. Ederington and Lee (1993) and Tanner (1997) show that information is reflected quickly in exchange rates so intraday data can capture market behaviours which are invisible in daily data. Moreover, in the same sample period, using a high sampling frequency increases the number of observations and leads to more reliable results. In spite of these advantages, high frequency data may pose a problem due to the high level of noise involved. In order to help alleviate this issue, we use the 5-minute sampling frequency as per the suggestion of Andersen (2000), who argues that it is probably the highest frequency possible that is not associated with an excessive amount of noise.

We contribute to the literature by being the first to examine the effect of the politically significant Brexit vote on the sterling, Euro and major safe-haven currencies in terms of their correlation and volatility transmission. The relationship between financial instruments have become more and more important due to the continuous expansion of current financial markets and the increasingly diverse choices of assets for investment readily available to market participants at any time. Investors now have to take into consideration a number of asset classes (e.g. equity, bond, currency, to name just a few) and each of these classes consists of a large and growing number of individual assets as well as numerous derivative products (e.g. futures, options and more) based on those assets. Moreover, since the correlation structure and volatility spillover among financial assets are not static and tend to vary over time, it is even more important to consider these aspects. They play an essential role in evaluating the risks involved in investments and thus can be highly useful in a wide range of practical applications such as risk management, portfolio selection, diversification, hedging and trading. For example, based on the level of correlation of financial securities with one another, one can (i) find potentially profitable opportunities for pairs trading (also known as statistical arbitrage) which is a relatively popular trading strategy that aims to take advantage of a temporary deviation from the usual co-movement of closely related instruments or (ii) identify the optimal hedge for an asset during its entire holding period using one or more other assets, which is often necessary in multiple aspects of financial planning. 
Following Antonakakis (2012), we apply the Dynamic Conditional Correlation (DCC) model of Engle (2002) for the correlation analysis and the approach of Diebold and Yilmaz (2012) to study the volatility transmission. Regarding the DCC model, we also apply the model of Aielli (2013), which ensures the consistency of the estimator. Meanwhile, Diebold and Yilmaz (2012) utilise the generalised VAR framework to produce improved variance decomposition which does not depend on the ordering of variables and hence is able to describe the relationship among markets more accurately (Dekker et al., 2001, Yang et al., 2003).

We find that since the directly involved currencies depreciate and the safe-haven currencies appreciate as a result of the vote, the correlation between the two groups decreases while the correlation within the latter group increases. Trading activities of the safe-haven currencies also increase, which is a sign of flight to quality. On the other hand, in line with the findings of Baele (2005) and Christiansen (2007) that volatility spillover has a positive correlation with the level of market integration, we find a large decrease of $64 \%$ in the volatility transmission between GBP and EUR after the announcement of voting results. However, there is still an overall increase in transmission among the currencies although the main source of forecast error variance of each currency is its own volatility persistence. In line with Lee and Rui (2002) and Baele (2005), there is a positive correlation between the net transmission of the currencies and their level of volatility and trading activities. Overall, we observe that the Brexit vote, which is a recent political event of great importance, has had significant impact on key aspects of the high frequency relationship among major instruments in the largest market of all, namely the foreign exchange market.

This paper proceeds as follows. Section 2 reviews the literature on the effect of political and unique events on financial markets. Section 3 and 4 describe the data and methodology used to study the correlation and volatility transmission among markets. Section 5 and 6 provide the results and conclusion respectively.

\section{Literature review}

In this section we review the literature on how financial markets are affected by political and unique events in general as well as by the Brexit vote in particular.

\subsection{Effect of political events}


Elections are among the most widely studied political events. Pantzalis et al. (2000) examine 33 countries from 1974 to 1995 and find that during the two-week period before an election, the market observes positive abnormal returns which depend on the country's level of political freedom and the election timing. In another multi-country study, Foerster and Schmitz (1997) point out that the returns also show some predictability after an election. They investigate 18 countries in four decades $(1957$ - 1996) and find that similar to the US, other stock markets show lower returns in the second year after a US presidential election. Therefore, US elections are an important systematic factor which affects international stock returns. However, in stark contrast to these findings, Döpke and Pierdzioch (2006) find that elections in Germany have no effect on the German equity market using data from 1960 to 2003. On the other hand, SantaClara and Valkanov (2003), based on a long dataset of more than 70 years (1927 - 1998), show that the excess return of the US market may change depending on which party wins the election. Interestingly, this difference exists not only around the election date and it cannot be explained by the business cycle or a risk premium. Yet again, Döpke and Pierdzioch (2006) find that this phenomenon does not hold in Germany and conclude that politics does not have much impact on the German market.

Elections affect not only market returns but also the return variance. Białkowski et al. (2008), who study 27 OECD countries during the 1980 - 2004 period, document that the countryspecific component of variance may double in the election week when the results surprise the market. The magnitude of this change depends on factors such as the margin of victory, changes in the political direction of the government and the maturity of the market. In addition to the equity market, the foreign exchange market is also affected by elections. In a study on Latin American countries from 1980 to 1996, Sibley (2001) find that presidential elections are related to currency depreciation which is most significant around inauguration and argue that the political cycle is an important determinant of exchange rates. Foerster and Schmitz (1997) observe a similar pattern in the longer term where the US dollar often depreciates more in the second year after the election.

Elections are not the only important political factor. Pastor and Veronesi (2012) note that when a policy change is announced, there is often a decrease in stock prices which is positively correlated with the uncertainty about the policy and also depends on whether that policy change follows an economic recession. Moreover, policy changes are associated with an increase in stock volatility, correlation and risk premium. Another source of political uncertainty, namely 
an uprising, is examined by Ahmed (2014), who confirms a uni-directional volatility transmission from the stock market to the foreign exchange market in Egypt before and during the uprising in 2011, showing the influence of equity on currency. Importantly, Boutchkova et al. (2012) argue that political uncertainty has more impact on some industries than on others. Industries which rely more on trade and labour become more volatile when political risks increase locally or in the countries of trading partners. Volatility decomposition indicates that the systematic and industry-specific volatility are affected by local and global political risks respectively.

\subsection{Effect of unique events}

In addition to political events, a number of unique events have been studied in the literature such as the Euro introduction, the collapse of Lehman Brothers and terrorist attacks. Dijk et al. (2011) investigate European currencies from 1994 to 2003 and discover that after the Euro introduction in 1999, there are significant structural breaks in the correlation among exchange rates and to a lesser extent, their volatility. McGroarty et al. (2006) document the important role of various microstructure effects in determining the bid-ask spread and volatility of currencies after the European Monetary Union (EMU) came into existence. In another paper, Legrand (2014) study seven countries adopting the Euro and three EU countries maintaining their own currencies and document that since 2000, the Euro-adopting countries have experienced a substantial increase in the influence of monetary shocks. In a study of 25 currencies during the 1999 - 2013 period, Eun et al. (2015) observe a decreasing level of exchange rate risks for Euro-based agents as well as increasing influence of the Euro on other currencies since its introduction.

Regarding the effects of the Euro on equity markets, Haselmann and Herwartz (2010) show a decrease in the home bias of German investors since the Euro was introduced which leads to a decrease in national investments and an increase in investments in other EMU countries and the US. Korkeamäki (2011) points out that for most Western European countries, the correlation between stock returns and interest rate changes is no longer negative since 1999. Using daily data of the 10 most developed equity markets in Europe between 1988 and 2012, Urquhart (2014) confirms that the Euro introduction is not an essential determinant of market efficiency because after this event, some markets have become more efficient while others have become less efficient. 
Another unique event, namely the failure of Lehman Brothers, has also been studied. Following the event, Baba and Packer (2009) look into the FX swap market between the US dollar and three major European currencies and find a negative correlation between deviations from the covered interest parity and the creditworthiness of US and European financial institutions. On the other hand, Chesney et al. (2011) analyse terrorist attacks in 25 countries in 11 years and conclude that terrorism has a significant negative impact on stock markets, especially on the airline and insurance industry. Similar to financial crashes and unlike natural disasters, terrorist attacks generally result in extreme returns on the event day but their influence weakens after the event.

\subsection{Effect of the Brexit vote}

Pain and Young (2004) argue that the UK will be affected negatively by its withdrawal from the EU due to a lower level of incoming foreign direct investment in the future. Moreover, Schiereck et al. (2016) find that the short-term negative stock return caused by the announcement of the vote is more significant than that caused by the bankruptcy of Lehman Brothers, especially for EU banks. Ramiah et al. (2016), who examine the British economy from June to July 2016, add that the effect of the Brexit vote is sector-specific and that the banking and travel sector in particular suffer from negative effects. Plakandaras et al. (2017) examine the effect of Brexit on the USD/GBP exchange rate and show that most of the depreciation is based on the uncertainty caused by Brexit, while Adesina (2017) finds that following the Brexit vote, volatility persistence increased significantly in stock markets, but decreased in the foreign exchange market.

On the other hand, Jackowicz et al. (2017) find that investors' reaction to the vote were uniform and surprisingly, exporters did not suffer the most while Oehler et al. (2017) find that firms with higher proportions of domestic sales realized more negative abnormal returns than stocks of firms with more sales abroad on the day after the vote. Tielmann and Schiereck (2017) study 107 logistic companies in the UK and EU and show that the UK companies have a significant poorer performance than logistic companies in the EU. Recently, Nishimura and Sun (2018) propose a new approach, the Intraday Volatility Spillover Index approach, and show no apparent change in the connectedness of European markets since the Brexit vote over a threemonth period but the volatility spillovers increase when they study the one-month since the vote. Aristeidis and Elias (2018) show that the significant referendum results cause immediate financial contagion and increased uncertainty but these were limited as most markets had fully 
recovered a few days after the polling day. Tata (2018) explain that 20-30\% of the UK-based corporate and investment banking will migrate into the European Economic Area after the vote.

In summary, we have reviewed the literature on the effect on financial markets of political and unique events as well as of the Brexit vote itself. These events have been found to have significant impacts on markets (i) of different types, especially equity and currency, (ii) in different aspects including returns, volatility, correlation, transmission, risks and efficiency, (iii) at different horizons (i.e. during and after the event) and (iv) with differences from sector to sector. We contribute to the literature by analysing the effect of the Brexit vote on the highfrequency correlation and volatility transmission among the sterling, Euro and other major currencies.

\section{Data}

Our dataset includes the currencies directly involved in the vote, namely the sterling (GBP) and Euro (EUR), and major safe-haven currencies, namely the Swiss franc (CHF), Japanese yen (JPY) and gold. We use the Thomson Reuters Tick History database to collect their 5minute exchange rates against USD from June 2015 to June 2017. We choose the 5-minute frequency because Andersen (2000) argues that frequencies higher than 5-minute are seriously distorted by noise. The sample period is chosen such that the period before and after the event are equally long as suggested by Antonakakis (2012). In line with how the currency market operates, our observations are collected around the clock and time-stamped in GMT.

Unlike many event studies, we use intraday data instead of daily data. However, the nature of our analysis does not depend on the data sampling frequency. Using intraday data, we treat the event day as a range of intraday observations. We use high frequency data because information is reflected quickly in the foreign exchange market (Ederington and Lee, 1993, Tanner, 1997). On the event day, the voting results were released in only a short period in the early morning so the market should react most strongly during this time. Such reactions are less visible in daily data and can be captured more effectively by intraday data. In fact, GBP depreciated by only $8.05 \%$ at the end of the event day but the depreciation was as much as $10.66 \%$ in the announcement period.

Following Marshall et al. (2013), we remove potential data errors by excluding unrealistic returns given the sampling frequency used (i.e. higher than $25 \%$ or lower than $-25 \%$ since a 
change of more than $25 \%$ in currency value in only 5 minutes is more likely to be a data error than an actual occurrence). We clean the data not because of our particular analysis but because it is important to use accurate data in general. Table 1 shows the summary statistics of the clean data. The mean returns of GBP, CHF and gold are negative while those of EUR and JPY are positive. The range of returns is largest for GBP (i.e. from $-4.6 \%$ to $1.3 \%$ ) and smallest for CHF (i.e. from $-0.9 \%$ to $0.9 \%$ ). On the other hand, the standard deviation is highest for gold $(0.06 \%)$ and lowest for EUR $(0.04 \%)$. Whereas the skewness differs among the currencies (i.e. negative for GBP, CHF and gold but positive for EUR and JPY), all of them are leptokurtic. As a result, the significant Jarque-Bera statistic confirms that these variables have a non-normal distribution. Figure 1 below plots the time series throughout the entire sample period.

Figure 1 shows an overview of the exchange rates during the sample period. There are gaps on the graphs because sometimes the market opens a new week at a much different price from the close price of the previous week. The most striking feature with regards to the trend is that prior to the Brexit vote, only GBP and JPY show a clear trend but in opposite directions (i.e. downward for GBP and upward for JPY). However, after the vote, only GBP shows a relatively clear trend, which is not surprising because GBP should have been affected more strongly by the vote than the other currencies. In addition, the post-vote trend of GBP is also downward and hence it is the only currency that has maintained a clear trend throughout the sample period. At the same time, GBP is also the only currency that has lost value during the whole period (i.e. a depreciation of $14.3 \%$ ) while all of the remaining currencies have gained value (i.e. EUR by $4.6 \%$, CHF by $1.3 \%$, JPY by $11 \%$ and gold by $4.4 \%$ ). GBP is different from the rest not only in terms of the direction of the overall change in value but also in terms of the magnitude of this change (i.e. $14.3 \%$ ).

\section{Methodology}

\subsection{Correlation}

Assuming that the currency returns follow an $\mathrm{AR}(\mathrm{p})$ process, they can be written as

$$
r_{t}=\mu+\sum_{i=1}^{p} \alpha_{i} r_{t-i}+\varepsilon_{t}
$$

where $r_{t}$ is a $5 \times 1$ vector of returns because there are five currencies in our study. 
$\mu$ is the $5 \times 1$ vector of intercepts.

$\varepsilon_{t}$ is the $5 \times 1$ vector of residuals.

The residuals can be written as

$$
\varepsilon_{t}=D_{t} u_{t}
$$

$D_{t}$ is the $5 \times 5$ diagonal matrix of volatility (i.e. square root of variance). The variances follow a univariate GARCH process. We use GARCH(1,1) since Hansen and Lunde (2005) show that for the currency market, the performance of $\operatorname{GARCH}(1,1)$ is comparable to that of more sophisticated models. $u_{t}$ is the $5 \mathrm{x} 1$ vector of standardised residuals and $u_{t} \sim N(0, I)$ where $I$ is the $5 \times 5$ identity matrix.

We employ the DCC model of Engle (2002), which measures the correlation among the currencies over time using the covariance of standardised residuals from the AR - GARCH process.

$$
Q_{t}=(1-\alpha-\beta) \bar{Q}+\alpha u_{t-1} u_{t-1}^{\prime}+\beta Q_{t-1}
$$

where $Q_{t}$ is the $5 \times 5$ covariance matrix of $u_{t}$.

$\bar{Q}$ is the $5 \times 5$ unconditional covariance matrix of $u_{t}$.

$u_{t}$ is the $5 \times 1$ vector of standardised residuals.

$\alpha$ and $\beta$ satisfy $\alpha \geq 0, \beta \geq 0$ and $\alpha+\beta<1$.

Letting $Q_{t}^{*}$ be the $5 \times 5$ diagonal variance matrix of $u_{t}$, Aielli (2013) suggests a slightly different specification of $Q_{t}$ to make the model more tractable.

$$
Q_{t}=(1-\alpha-\beta) \bar{Q}+\alpha\left[Q_{t-1}^{* 1 / 2} u_{t-1} u_{t-1}^{\prime} Q_{t-1}^{* 1 / 2}\right]+\beta Q_{t-1}
$$

The $5 \times 5$ correlation matrix $R_{t}$ is given by

$$
R_{t}=Q_{t}^{*-1 / 2} Q_{t} Q_{t}^{*-1 / 2}
$$

We test different model parameters (i) with different AR lags, (ii) with or without the asymmetric GARCH term used by Cappiello et al. (2006) and (iii) with or without the improvement by Aielli (2013). Based on the Akaike information criterion, the best model is $\operatorname{AR}(0)-\operatorname{GARCH}(1,1)$ with the improvement by Aielli (2013).

\subsection{Volatility transmission}

Adopting the approach of Diebold and Yilmaz (2012) to analyse the volatility transmission among currencies, we employ the generalised VAR framework to produce improved variance 
decomposition which does not depend on the ordering of variables. For each variable, variance decomposition shows how much of its forecast error variance is due to shocks to itself and the other variables. Let us start with the following VAR system.

$$
y_{t}=\sum_{i=1}^{p} \Theta_{i} y_{t-i}+\varepsilon_{t}
$$

where $y_{t}$ is the $5 \mathrm{x} 1$ vector of the currency variables.

$\Theta_{i}$ is the $5 \times 5$ coefficient matrix.

$\varepsilon_{t}$ is the $5 \times 1$ vector of residuals and $\varepsilon_{t} \sim(0, \Sigma)$.

The VAR system can be transformed to the following moving average model.

$$
y_{t}=\sum_{i=0}^{\infty} A_{i} \varepsilon_{t-i}
$$

where $A_{i}$ is the $5 \times 5$ coefficient matrix which satisfies $A_{i}=\sum_{j=1}^{p} \Theta_{j} A_{i-j}$ and $A_{0}$ is the identity matrix. According to (7), the value of $y$ at time $t+s$ is given by

$$
y_{t+s}=\sum_{i=0}^{\infty} A_{i} \varepsilon_{t+s-i}
$$

On the other hand, the forecast of $y_{t+s}$ based on the information available at time $t$ is

$$
\hat{y}_{t+s \mid t}=\sum_{i=s}^{\infty} A_{i} \varepsilon_{t+s-i}
$$

Therefore, the forecast error is

$$
y_{t+s}-\hat{y}_{t+s \mid t}=\sum_{i=0}^{s-1} A_{i} \varepsilon_{t+s-i}
$$

Diebold and Yilmaz (2012) show that the contribution of variable m's shocks to the s-stepahead forecast error variance of variable $\mathrm{n}$ is given by

$$
\theta_{m \rightarrow n}^{(s)}=\frac{\sigma_{m m}^{-1} \sum_{i=0}^{s-1}\left(e_{n}^{\prime} A_{i} \sum e_{m}\right)^{2}}{\sum_{i=0}^{s-1}\left(e_{n}^{\prime} A_{i} \sum A_{i}^{\prime} e_{n}\right)}
$$

where $\sigma_{m m}$ is the standard deviation of shocks to variable $m$.

$\sum$ is the $5 \times 5$ covariance matrix of the shocks. As a result, $A_{i} \sum A_{i}^{\prime}$ is the $5 \times 5$ covariance matrix of the effects of shocks. 
$e_{n}$ and $e_{m}$ are $5 \times 1$ selection vectors whose elements take the value of one when corresponding to variable $\mathrm{n}$ and $\mathrm{m}$, and zero otherwise. $n=m$ refers to the contribution of a variable's own shocks while $n \neq m$ refers to the contribution of shocks from the other variables.

Because the shocks to the variables may be correlated, the contributions of all variables to the forecast error variance of each of them may not add to one. Hence, the contribution of each variable is normalised so that their total contribution to each of them is equal to one.

$$
\tilde{\theta}_{m \rightarrow n}^{(s)}=\frac{\theta_{m \rightarrow n}^{(s)}}{\sum_{m=1}^{5} \theta_{m \rightarrow n}^{(s)}}
$$

Based on the variance decomposition, we can calculate several quantities of interest including the total volatility spillover index, net spillovers and net pairwise spillovers.

1. The total volatility spillover index measures how much of the total forecast error variance of all variables is due to shocks to all the other variables (i.e. not due to shocks to themselves).

$$
V^{(s)}=\frac{\sum_{m, n=1 ; m \neq n}^{5} \tilde{\theta}_{m \rightarrow n}^{(s)}}{\sum_{m, n=1}^{5} \tilde{\theta}_{m \rightarrow n}^{(s)}} * 100
$$

2. The net spillover of each variable measures the difference between the volatility it gives to and the volatility it receives from all the other variables.

$$
V_{n-\sum m}^{(s)}=\sum_{m=1, m \neq n}^{5}\left(\tilde{\theta}_{n \rightarrow m}^{(s)}-\tilde{\theta}_{m \rightarrow n}^{(s)}\right) * 100
$$

3. The net pairwise spillover measures the difference between the volatility one currency in the pair gives to and the volatility it receives from the other currency.

$$
V_{n-m}^{(s)}=\left(\tilde{\theta}_{n \rightarrow m}^{(s)}-\tilde{\theta}_{m \rightarrow n}^{(s)}\right) * 100
$$

A potential question at this point is whether the classical event study approach can be used instead of our chosen method. It may be possible but there are some issues. To our knowledge, the traditional approach is used to analyse individual instruments (usually their returns) more often than their relationship with one another. When the focus is the relationship and interaction (e.g. the correlation and volatility transmission in our work), the number of quantities of interest is likely to increase significantly. In our case, there are 5 financial assets so the number of quantities of interest is 10 regarding correlation and 25 regarding volatility spillover. We find 
it difficult to concisely report these results in a classical event study. Moreover, it has been found that event studies are less reliable at long horizons (see Kothari and Warner (2007) for a detailed discussion).

\section{Results}

Before discussing the results, we would like to note that the event date in this study is the announcement date of voting results $(24 / 06 / 2016$, the day after the vote) because the market is more likely to react to the actual results than to the vote itself. There is another possible event, namely the announcement of the vote date on 20/02/2016 which introduced the possibility of Brexit. However, it was only a possibility at that point and not a decision so the market response was much weaker on 20/02 than on 24/06, which suggests that the chosen event date is indeed more important. Specifically, GBP depreciated only about $2 \%$ on $20 / 02$ but more than $8 \%$ on 24/06 due to the surprising referendum outcome (Schiereck et al., 2016). In the future, a potential event will be the completion date of the Brexit transition phase when the UK officially leaves the EU.

\subsection{Correlation}

Figure 2 shows that among all 10 pairs, the pair of EUR and CHF is the least volatile since their correlation coefficient tends to remain in a relatively tight range compared to the other pairs, ranging only from around $-50 \%$ to around $-80 \%$. More importantly, the Brexit vote triggers significant reaction from many currency pairs, evidenced by large spikes around the event (i.e. in the middle area of the graphs) which stand out from the remaining period. The most substantial reaction is observed in the pairs between the three European currencies and JPY or gold (i.e. GBP - JPY, GBP - gold, EUR - JPY, EUR - gold, CHF - JPY and CHF gold). Among these six pairs, the correlation increases for the CHF - JPY and CHF - gold pair while it decreases for the other pairs. Interestingly, the reaction of these six pairs to the vote has changed the sign of their usual correlation coefficients. To be more specific, (i) for the GBP - JPY pair and the GBP - gold pair, their usual positive correlation of around $15 \%$ decreases to as low as $-90 \%$, (ii) for the EUR - JPY pair and the EUR - gold pair, their usual positive correlation of around $35 \%$ decreases to around $-75 \%$, and (iii) for the CHF - JPY pair and the $\mathrm{CHF}$ - gold pair, their usual negative correlation of around $-35 \%$ increases to as high as $60 \%$. In spite of the great magnitude of those changes, this effect is temporary because afterwards the correlation coefficients resume their pre-vote behaviours. 
Regarding the alternative method of traditional event study discussed at the end of the Methodology section, it would probably lead to similar findings. For example, let us look at the EUR - JPY correlation chart in Figure 2. The correlation is mostly about $40 \%$ both before and after the event and there is a downward spike around the event. Using the traditional approach, we would obtain the abnormal post-event changes by subtracting the expected values from the actual values. Assuming that the expected correlation is the average pre-event value (i.e. around $40 \%$ ), the changes in correlation after the event would be mostly around zero and there would still be a downward spike around the event. Therefore the classical event study would produce a similar pattern (i.e. a downward spike followed by a normal period). To better understand the market reaction to the voting results, we examine the returns and changes in trading activities of the currencies on the event day in Table 2.

The changes in number of trades as well as in trading volume reported in Table 2 show that trading activities increase for all currencies. Regarding the number of trades, gold has the smallest increase (40.95\%) while EUR has the largest increase $(103.71 \%)$. Regarding the trading volume, EUR and GBP have the smallest and largest increase respectively $(72.93 \%$ and $502.11 \%)$. On the other hand, GBP has the lowest return $(-8.05 \%)$ whereas gold has the highest return (4.69\%). In terms of the relationship between returns and trading activities, Evans and Lyons (2002) find that currency returns depend on the signed volume. Specifically, positive returns result from net purchases and negative returns result from net sales. Therefore, the depreciation of the currencies directly involved in the vote (i.e. $-8.05 \%$ for GBP and $-2.35 \%$ for EUR) indicates their net sales and the appreciation of the safe-haven currencies (i.e. $1.46 \%$ for CHF, $3.85 \%$ for JPY and $4.69 \%$ for gold) indicates their net purchases, both of which represent a flight to quality of investors.

\subsection{Volatility transmission}

In addition to the correlation among the currencies, we also investigate another aspect of their relationship in Table 3, namely the volatility transmission which is measured by their contribution to the forecast error variance of one another.

According to Table 3, the largest contribution to the forecast error variance of each variable comes from its own volatility (i.e. the diagonal values) which ranges from around 55 (i.e. EUR both before and after the vote) to around 80 (i.e. GBP both before and after the vote as well as 
gold before the vote). However, the spillover index is 31.65 prior to the Brexit vote and 33.92 following the vote, which shows that the overall volatility transmission has increased by $7.2 \%$ after this event. In particular, EUR gives and receives the most volatility in both the pre-vote period (i.e. 56.32 and 45.62 respectively) and the post-vote period (i.e. 50.47 and 43.77 respectively). Meanwhile, gold gives and receives the least pre-vote volatility (i.e. 16.74 and 21.27 respectively) and GBP gives and receives the least post-vote volatility (i.e. 15.75 and 21.6 respectively). After the vote, the net volatility transmission of GBP and EUR decreases (i.e. from -5.55 to -5.85 for GBP and from 10.71 to 6.7 for EUR) whereas that of the safe-haven currencies increases (i.e. from 3.03 to 3.45 for CHF, from -3.66 to -1.77 for JPY and finally from -4.53 to -2.54 for gold). Motivated by Lee and Rui (2002) and Baele (2005), we examine the potential relation of these changes to changes in their volatility and trading activities in Table 4.

For EUR, CHF and gold, their volatility changes in the same direction as their net volatility transmission (Table 3) with a decrease for EUR (-16.19\%) and an increase for CHF $(17.36 \%)$ and gold (2.05\%), which is consistent with Baele (2005), who finds a positive correlation between volatility spillover and the level of volatility. Table 4 also shows that for all currencies except GBP, the volatility is positively correlated with the trading volume (i.e. both are negative for EUR and JPY but positive for CHF and gold), which is consistent with Lee and Rui (2002). In turn, the changes in volume in particular and in trading activities in general may be explained by the market's reaction to the Brexit vote. Despite the negligible decrease in the GBP volume $(-0.11 \%)$, the large increase in its number of trades $(41.31 \%)$ indicates the market's continued interest in GBP but mainly as a target for selling activities, evidenced by its negative return in the post-vote period $(-12.45 \%)$. EUR is also affected by the vote but perhaps less than GBP so it is less appealing for selling activities and the market's interest in EUR decreases, as shown by its negative volume change $(-12.93 \%)$. On the other hand, the market becomes more interested in the safe-haven currencies, which increases their volume and number of trades except the JPY volume (-18.14\%). To better understand the pairwise interaction of the currencies, we report their net pairwise volatility transmission in Table 5.

Table 5 shows that the Brexit vote has the most consistent effects on EUR and gold because the changes in net pairwise transmission of EUR (i.e. the EUR column in Panel C) are all negative (i.e. ranging from -0.11 to -1.73 ) and those of gold (i.e. the gold column in Panel C) 
are all positive (i.e. ranging from 0.12 to 1.16 ). On the other hand, the vote has the most mixed effects on CHF (i.e. the CHF column in Panel C) with two negative values and two positive values which range from -0.49 to 1 . More interestingly, these changes of EUR and gold are positively correlated with the changes in their volatility (Table 4), which is again consistent with Baele (2005).

While the current five-variable VAR system provides an overview of volatility spillover in the currency market in general, we are most interested in the GBP - EUR pair since they are directly involved in the vote. However, in the current specification, changes in the interaction between GBP and EUR as a result of Brexit may be distorted by the inclusion of the other assets in the model because they are less relevant to this particular event, which is similar to how adding less relevant variables to a regression will deteriorate the coefficient estimates of more relevant variables. Therefore, we redo the variance decomposition of GBP and EUR in a two-variable VAR system in Table 6, which is more consistent with our focus on Brexit. Moreover in practice, some traders only concentrate on a small number of instruments (Rinne and Suominen, 2016) so those specialised in trading GBP and EUR may be more interested in this specification.

Table 6 shows that the forecast error variance of GBP and EUR is mostly due to their own volatility (i.e. the diagonal values) which ranges from around 85 (i.e. EUR before the vote) to around 95 (i.e. both GBP and EUR after the vote). Moreover, after the Brexit vote, there was a large decrease in (i) the volatility GBP gives EUR (decreasing 62\% from 14.56 to 5.55), (ii) the volatility EUR gives GBP (decreasing 66\% from 11.12 to 3.76 ), (iii) the net volatility transmission of GBP (decreasing $48 \%$ from 3.44 to 1.78) and (iv) the overall volatility transmission (decreasing 64\% from 12.84 to 4.66). This decrease in the volatility transmission between GBP and EUR following the vote is consistent with Baele (2005) and Christiansen (2007), who find a positive correlation between volatility spillover and the level of market integration.

\section{Conclusion}

Ours is the first study on the effect of the Brexit vote, an international political event, on the foreign exchange market, the largest market currently in existence. Using high-frequency data to accommodate the fast-moving FX market, we examine the correlation and volatility 
transmission among major currencies before and after the vote. For the correlation analysis, we apply the DCC model of Engle (2002) and Aielli (2013). To analyse the volatility transmission, we utilise the improved variance decomposition technique based on the generalised VAR framework. In general, we show that these important aspects of the relationship among the currencies have experienced significant changes following the vote.

After the vote, there was a decrease in the correlation between the directly involved currencies (i.e. GBP and EUR) and the safe-haven currencies (i.e. CHF, JPY and gold) while there was an increase in the correlation among the safe-haven currencies. These changes were caused by the depreciation of GBP and EUR and the appreciation of the safe-haven currencies in response to the event. There was also an increase in the trading activities of the safe-haven currencies, which indicates a flight to quality. Regarding the volatility transmission, there was a significant decrease of $64 \%$ in the transmission between GBP and EUR following the Brexit vote, which is consistent with Baele (2005) and Christiansen (2007), who find that volatility spillover is positively correlated with the level of market integration. However, volatility transmission among the currencies has increased in general although most of the forecast error variance of each variable still comes from its own volatility persistence. Consistent with Lee and Rui (2002) and Baele (2005), the net transmission of the currencies is positively correlated with their level of volatility and changes in their trading activities as a result of the vote. In summary, we find that the Brexit vote has had significant effects on the foreign exchange market in terms of correlation and volatility transmission. 


\section{References}

ADESINA, T. 2017. Estimating volatility persistence under a Brexit-vote structural break. Finance Research Letters, 23, 65-68.

AHMED, W. M. A. 2014. Dynamic Interactions between Egyptian Equity and Currency Markets Prior to and during Political Unrest. Applied Financial Economics, 24, 1347-1359.

AIELLI, G. P. 2013. Dynamic Conditional Correlation: On Properties and Estimation. Journal of Business and Economic Statistics, 31, 282-299.

ANDERSEN, T. G. 2000. Some Reflections on Analysis of High-Frequency Data. Journal of Business \& Economic Statistics, 18, 146-153.

ANGELO, R. \& PAUL, S. 2010. Safe Haven Currencies. Review of Finance, 14, 385.

ANTONAKAKIS, N. 2012. Exchange return co-movements and volatility spillovers before and after the introduction of euro. Journal of International Financial Markets, Institutions \& Money, 22, 1091-1109.

ARISTEIDIS, S. \& ELIAS, K. 2018. Empirical analysis of market reactions to the UK's referendum results - How strong will Brexit be? Journal of International Financial Markets, Institutions and Money, 53, 263-286.

BABA, N. \& PACKER, F. 2009. From turmoil to crisis: Dislocations in the FX swap market before and after the failure of Lehman Brothers. Journal of International Money \& Finance, 28, 13501374.

BAELE, L. 2005. Volatility Spillover Effects in European Equity Markets. Journal of Financial \& Quantitative Analysis, 40, 373-401.

BAUR, D. G. \& LUCEY, B. M. 2010. Is Gold a Hedge or a Safe Haven? An Analysis of Stocks, Bonds and Gold. The Financial Review, 45, 217-229.

BAUR, D. G. \& MCDERMOTT, T. K. 2010. Is gold a safe haven? International evidence. Journal of Banking and Finance, 34, 1886-1898. 
BESSEMBINDER, H. 1994. Bid - ask spreads in the interbank foreign exchange markets. Journal of Financial Economics, 35, 317-348.

BIAŁKOWSKI, J., GOTTSCHALK, K. \& WISNIEWSKI, T. P. 2008. Stock market volatility around national elections. Journal of Banking and Finance, 32, 1941-1953.

BOUTCHKOVA, M., HITESH, D., DURNEV, A. \& MOLCHANOV, A. 2012. Precarious Politics and Return Volatility. Review of Financial Studies, 25, 1111-1154.

BREDIN, D., CONLON, T. \& POTì, V. 2015. Does gold glitter in the long-run? Gold as a hedge and safe haven across time and investment horizon. International Review of Financial Analysis, 41, 320328.

CAPPIELLO, L., ENGLE, R. F. \& SHEPPARD, K. 2006. Asymmetric Dynamics in the Correlations of Global Equity and Bond Returns. Journal of Financial Econometrics, 4, 537-572.

CHESNEY, M., RESHETAR, G. \& KARAMAN, M. 2011. The impact of terrorism on financial markets: An empirical study. Journal of Banking and Finance, 35, 253-267.

CHRISTIANSEN, C. 2007. Volatility-Spillover Effects in European Bond Markets. European Financial Management, 13, 923-948.

DE BOCK, R. \& FILHO, I. D. 2015. The behavior of currencies during risk-off episodes. Journal of International Money and Finance, 53, 218-234.

DEKKER, A., SEN, K. \& YOUNG, M. R. 2001. Equity market linkages in the Asia Pacific region: A comparison of the orthogonalised and generalised VAR approaches. Global Finance Journal, $12,1-33$.

DIEBOLD, F. X. \& YILMAZ, K. 2012. Better to give than to receive: Predictive directional measurement of volatility spillovers. International Journal of Forecasting, 28, 57-66.

DIJK, D. V., MUNANDAR, H. \& HAFNER, C. M. 2011. The euro introduction and noneuro currencies. Applied Financial Economics, 21, 95-116.

DÖPKE, J. \& PIERDZIOCH, C. 2006. Politics and the stock market: Evidence from Germany. European Journal of Political Economy, 22, 925-943.

EDERINGTON, L. H. \& LEE, J. H. 1993. How Markets Process Information: News Releases and Volatility. Journal of Finance, 48, 1161-1191.

ENGLE, R. 2002. Dynamic Conditional Correlation: A Simple Class of Multivariate Generalized Autoregressive Conditional Heteroskedasticity Models. Journal of Business \& Economic Statistics, 20, 339-350.

EUN, C. S., KIM, S.-H. \& LEE, K. 2015. Currency competition between the dollar and euro: Evidence from exchange rate behaviors. Finance Research Letters, 12, 100-108.

EVANS, M. D. D. \& LYONS, R. K. 2002. Order Flow and Exchange Rate Dynamics. Journal of Political Economy, 110, 170-180.

FATUM, R. \& YAMAMOTO, Y. 2016. Intra-safe haven currency behavior during the global financial crisis. Journal of International Money and Finance, 66, 49-64.

FOERSTER, S. R. \& SCHMITZ, J. J. 1997. The Transmission of U.S. Election Cycles to International Stock Returns. Journal of International Business Studies, 28, 1-27.

GRISSE, C. \& NITSCHKA, T. 2015. On financial risk and the safe haven characteristics of Swiss franc exchange rates. Journal of Empirical Finance, 32, 153-164.

HANSEN, P. R. \& LUNDE, A. 2005. A forecast comparison of volatility models: Does anything beat a GARCH(1,1)? Journal of Applied Econometrics, 20, 873-889.

HASELMANN, R. \& HERWARTZ, H. 2010. The introduction of the Euro and its effects on portfolio decisions. Journal of International Money \& Finance, 29, 94-110.

JACKOWICZ, K., KOZŁOWSKI, Ł. \& PODGÓRSKI, B. 2017. The distant echo of Brexit: Did exporters suffer the most? Finance Research Letters, 21, 132-139.

KORKEAMÄKI, T. 2011. Interest rate sensitivity of the European stock markets before and after the euro introduction. Journal of International Financial Markets, Institutions \& Money, 21, 811831.

KOTHARI, S. P. \& WARNER, J. B. 2007. Econometrics of Event Studies, Elsevier. 
LEE, B.-S. \& RUI, O. M. 2002. The dynamic relationship between stock returns and trading volume: Domestic and cross-country evidence. Journal of Banking and Finance, 26, 51-78.

LEGRAND, R. 2014. Euro introduction: Has there been a structural change? Study on 10 European Union countries. Economic Modelling, 40, 136-151.

MARSHALL, B., NGUYEN, N. H. \& VISALTANACHOTI, N. 2013. ETF arbitrage: Intraday evidence. Journal of Banking \& Finance, 37, 3486-3498.

MCGROARTY, F., AP GWILYM, O. \& THOMAS, S. 2006. Microstructure effects, bid-ask spreads and volatility in the spot foreign exchange market pre and post-EMU. Global Finance Journal, 17, 23-49.

NISHIMURA, Y. \& SUN, B. 2018. The intraday volatility spillover index approach and an application in the Brexit vote. Journal of International Financial Markets, Institutions \& Money, 55, 241-253.

OEHLER, A., HORN, M. \& WENDT, S. 2017. Brexit: Short-term stock price effects and the impact of firm-level internationalization. Finance Research Letters, 22, 175-181.

PAIN, N. \& YOUNG, G. 2004. The macroeconomic impact of UK withdrawal from the EU. Economic Modelling, 21, 387-408.

PANTZALIS, C., STANGELAND, D. A. \& TURTLE, H. J. 2000. Political Elections and the Resolution of Uncertainty: The International Evidence. Journal of Banking and Finance, 24, 1575-1604.

PASTOR, L. U. \& VERONESI, P. 2012. Uncertainty about Government Policy and Stock Prices. Journal of Finance, 67, 1219-1264.

PLAKANDARAS, V., GUPTA, R. \& WOHAR, M. E. 2017. The depreciation of the pound post-Brexit: Could it have been predicted? Finance Research Letters, 21, 206-213.

RAMIAH, V., PHAM, H. N. A. \& MOOSA, I. 2016. The sectoral effects of Brexit on the British economy: early evidence from the reaction of the stock market. Applied Economics, 49, 2508-2514.

RINNE, K. \& SUOMINEN, M. 2016. How some bankers made a million by trading just two securities? Journal of Empirical Finance.

SANTA-CLARA, P. \& VALKANOV, R. 2003. The Presidential Puzzle: Political Cycles and the Stock Market. Journal of Finance, 58, 1841-1872.

SCHIERECK, D., KIESEL, F. \& KOLARIC, S. 2016. Brexit: (Not) another Lehman moment for banks? Finance Research Letters, 19, 291-297.

SIBLEY, M. 2001. The Impact of Presidential Elections on Currency Values in Latin America. Multinational Business Review, 9, 14-19.

TANNER, G. 1997. A Note on Economic News and Intraday Exchange Rates. Journal of Banking and Finance, 21, 573-585.

TATA, F. 2018. Client-proximity-based spatial clustering of European corporate and investment banking after a hard Brexit. Finance Research Letters.

TIELMANN, A. \& SCHIERECK, D. 2017. Arising borders and the value of logistic companies: Evidence from the Brexit referendum in Great Britain. Finance Research Letters, 20, 22-28.

URQUHART, A. 2014. The Euro and European stock market efficiency. Applied Financial Economics, 24, $1235-1248$.

YANG, J., KOLARI, J. W. \& MIN, I. 2003. Stock market integration and financial crises: The case of Asia. Applied Financial Economics, 13, 477-486. 
Table 1. Summary statistics of 5-minute returns. The currencies are priced in USD. The returns are in percentage terms. $* * *$ superscript denotes statistical significance at $1 \%$ level.

\begin{tabular}{|lccccc|}
\hline & GBP & EUR & CHF & JPY & Gold \\
\hline Mean & $-6.36 \mathrm{E}-05$ & $4.06 \mathrm{E}-05$ & $-4.29 \mathrm{E}-05$ & $8.88 \mathrm{E}-05$ & $-2.78 \mathrm{E}-05$ \\
Median & 0.000 & 0.000 & 0.000 & 0.000 & 0.000 \\
Maximum & 1.348 & 0.999 & 0.897 & 2.893 & 1.381 \\
Minimum & -4.594 & -0.982 & -0.852 & -1.666 & -2.131 \\
Standard deviation & 0.044 & 0.037 & 0.042 & 0.042 & 0.056 \\
Skewness & -10.509 & 0.312 & -0.107 & 4.256 & -0.168 \\
Kurtosis & $999.777^{* *}$ & 44.556 & 17.130 & 293.766 & 41.195 \\
Jarque-Bera normality & $6.10 \mathrm{E}+09^{* * *}$ & $1.06 \mathrm{E}+07^{* * *}$ & $1.22 \mathrm{E}+06^{* * *}$ & $5.19 \mathrm{E}+08^{* * *}$ & $8.95 \mathrm{E}+06^{* * *}$ \\
\hline
\end{tabular}


Table 2. Returns and changes in trading activities. This table shows the returns and changes in the number of trades and in the trading volume of the currencies on the event day. Since the spot FX volume is not available to us, we use the FX futures volume of the Chicago Mercantile Exchange as its proxy, following Bessembinder (1994), who argues that they are highly correlated. The change in trading activities on the event day is calculated relative to the normal level of activities which is the average daily number of trades and trading volume of the period before the announcement of the Brexit vote in February 2016.

\begin{tabular}{|cccccc|}
\hline & GBP & EUR & CHF & JPY & Gold \\
\hline Return & $-8.05 \%$ & $-2.35 \%$ & $1.46 \%$ & $3.85 \%$ & $4.69 \%$ \\
Change in number of trades & $58.16 \%$ & $103.71 \%$ & $51.08 \%$ & $87.46 \%$ & $40.95 \%$ \\
Change in trading volume & $502.11 \%$ & $72.93 \%$ & $87.58 \%$ & $113.50 \%$ & $319.08 \%$ \\
\hline
\end{tabular}


Table 3. Volatility transmission. Panel A and B show the variance decomposition of the currencies before and after the Brexit vote respectively. Each row shows the contribution (\%) of the five instruments to the s-step-ahead forecast error variance of each of them (e.g. the first row shows how much of the GBP variance comes from each of the five instruments). Using 5-minute data, we set s to 12 which translates to one hour. The 'to others' and 'from others' values are the sum of the corresponding columns and rows excluding the diagonal values and they show how much volatility each instrument gives to and receives from the others. The 'net' values are 'to others' minus 'from others'. The spillover index (\%) is the sum of all 'to others' values divided by the total volatility of all instruments and it shows how much of their volatility is due to volatility transmission.

\begin{tabular}{|ccccccc|}
\hline & GBP & EUR & CHF & JPY & Gold & From others \\
\hline Panel A: pre-vote & & & & & & \\
GBP & 77.45 & 13.26 & 6.79 & 0.67 & 1.84 & 22.55 \\
EUR & 9.35 & 54.38 & 21.76 & 9.70 & 4.82 & 45.62 \\
CHF & 5.15 & 23.32 & 60.35 & 7.69 & 3.50 & 39.65 \\
JPY & 0.62 & 12.62 & 9.34 & 70.83 & 6.59 & 29.17 \\
Gold & 1.89 & 7.13 & 4.80 & 7.45 & 78.73 & 21.27 \\
To others & 17.01 & 56.32 & 42.68 & 25.50 & 16.74 & Spillover index \\
Net & -5.55 & 10.71 & 3.03 & -3.66 & -4.53 & 31.65 \\
\hline Panel B: post-vote & & & & & & \\
GBP & 78.40 & 13.38 & 7.06 & 0.42 & 0.74 & 21.60 \\
EUR & 9.58 & 56.23 & 23.53 & 5.72 & 4.93 & 43.77 \\
CHF & 5.22 & 24.10 & 59.13 & 6.58 & 4.96 & 40.87 \\
JPY & 0.27 & 6.91 & 7.73 & 67.44 & 17.65 & 32.56 \\
Gold & 0.68 & 6.08 & 5.99 & 18.07 & 69.18 & 30.82 \\
To others & 15.75 & 50.47 & 44.32 & 30.79 & 28.28 & Spillover index \\
Net & -5.85 & 6.70 & 3.45 & -1.77 & -2.54 & 33.92 \\
\hline
\end{tabular}


Table 4. Changes in volatility and trading activities. This table shows the changes in volatility, number of trades and trading volume of the currencies in the post-vote period. The volatility over time is obtained from the Dynamic Conditional Correlation model. The changes in each quantity are calculated based on the average value in the post-vote period relative to the average value in the pre-vote period.

\begin{tabular}{|cccccc|}
\hline & GBP & EUR & CHF & JPY & Gold \\
\hline Change in volatility & $22.86 \%$ & $-16.19 \%$ & $17.36 \%$ & $-7.76 \%$ & $2.05 \%$ \\
Change in number of trades & $41.31 \%$ & $58.17 \%$ & $6.74 \%$ & $85.31 \%$ & $44.81 \%$ \\
Change in trading volume & $-0.11 \%$ & $-12.93 \%$ & $10.88 \%$ & $-18.14 \%$ & $29.69 \%$ \\
\hline
\end{tabular}


Table 5. Pairwise volatility transmission. Panel A and B are derived from Table 3 and show the net volatility transmission in each pair of instruments before and after the Brexit vote respectively. For example, the first value in the second row is the volatility GBP gives EUR minus the volatility GBP receives from EUR. The diagonal values are zero because the volatility an instrument gives to and receives from itself are equal. Panel C is Panel B minus Panel A and shows the change in net pairwise transmission after the vote.

\begin{tabular}{|cccccc|}
\hline & GBP & EUR & CHF & JPY & Gold \\
\hline Panel A: pre-vote & & & & & \\
GBP & 0.00 & 3.91 & 1.65 & 0.04 & -0.05 \\
EUR & -3.91 & 0.00 & -1.56 & -2.92 & -2.31 \\
CHF & -1.65 & 1.56 & 0.00 & -1.65 & -1.30 \\
JPY & -0.04 & 2.92 & 1.65 & 0.00 & -0.86 \\
Gold & 0.05 & 2.31 & 1.30 & 0.86 & 0.00 \\
\hline Panel B: post-vote & & & & & \\
GBP & 0.00 & 3.80 & 1.84 & 0.15 & 0.06 \\
EUR & -3.80 & 0.00 & -0.57 & -1.19 & -1.15 \\
CHF & -1.84 & 0.57 & 0.00 & -1.15 & -1.03 \\
JPY & -0.15 & 1.19 & 1.15 & 0.00 & -0.43 \\
Gold & -0.06 & 1.15 & 1.03 & 0.43 & 0.00 \\
\hline Panel C: B-A & & & & & \\
GBP & 0.00 & -0.11 & 0.19 & 0.10 & 0.12 \\
EUR & 0.11 & 0.00 & 1.00 & 1.73 & 1.16 \\
CHF & -0.19 & -1.00 & 0.00 & 0.49 & 0.27 \\
JPY & -0.10 & -1.73 & -0.49 & 0.00 & 0.43 \\
Gold & -0.12 & -1.16 & -0.27 & -0.43 & 0.00 \\
\hline
\end{tabular}


Table 6. GBP - EUR volatility transmission. Panel A and B show the variance decomposition of GBP and EUR in a two-variable VAR system before and after the Brexit vote respectively. Each row shows the contribution (\%) of both currencies to the forecast error variance of each of them. The 'to others' and 'from others' values are the sum of the corresponding columns and rows excluding the diagonal values and they show how much volatility each instrument gives to and receives from the other. The 'net' values are 'to others' minus 'from others'. The spillover index (\%) is the sum of both 'to others' values divided by the total volatility of both instruments and it shows how much of their volatility is due to volatility transmission.

\begin{tabular}{|cccc|}
\hline & GBP & EUR & From others \\
\hline Panel A: pre-vote & & & \\
GBP & 88.88 & 11.12 & 11.12 \\
EUR & 14.56 & 85.44 & 14.56 \\
To others & 14.56 & 11.12 & Spillover index \\
Net & 3.44 & -3.44 & 12.84 \\
\hline Panel B: post-vote & & & \\
GBP & 96.24 & 3.76 & 3.76 \\
EUR & 5.55 & 94.45 & 5.55 \\
To others & 5.55 & 3.76 & Spillover index \\
Net & 1.78 & -1.78 & 4.66 \\
\hline
\end{tabular}


Figure 1. Exchange rates over time. This figure shows the daily exchange rates during the whole sample period. The vertical axis shows the price of each currency in terms of the US dollar (i.e. how many dollars are equivalent to one unit of the currency in question). The sample period is from June 2015 to June 2017 and the Brexit vote in June 2016 is marked in red on the graphs.

\section{GBP}

1.7000

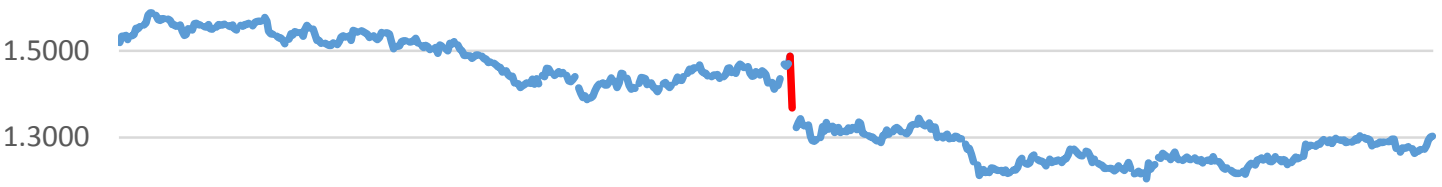

1.1000

EUR

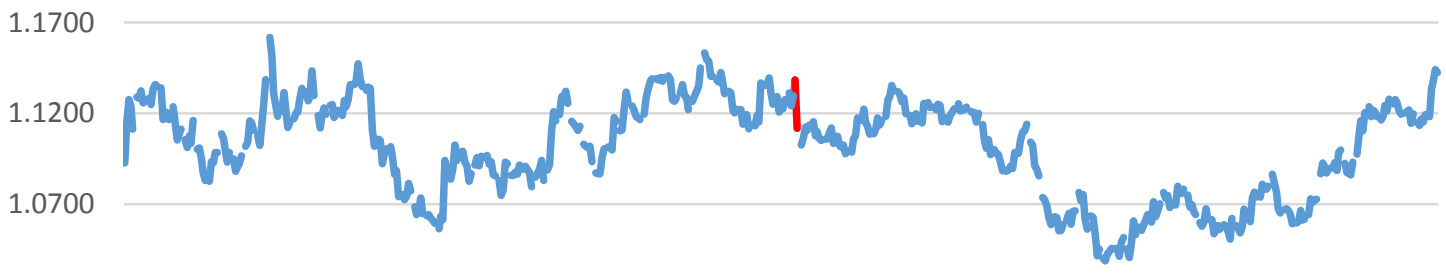

1.0200

$\mathrm{CHF}$

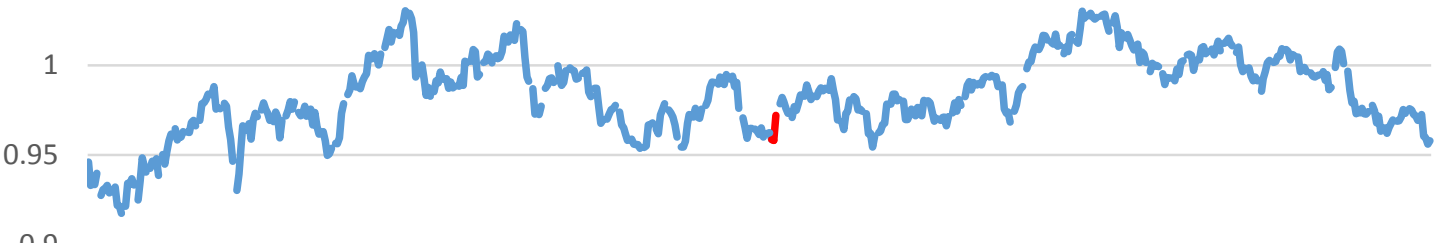

0.9

JPY

0.0105

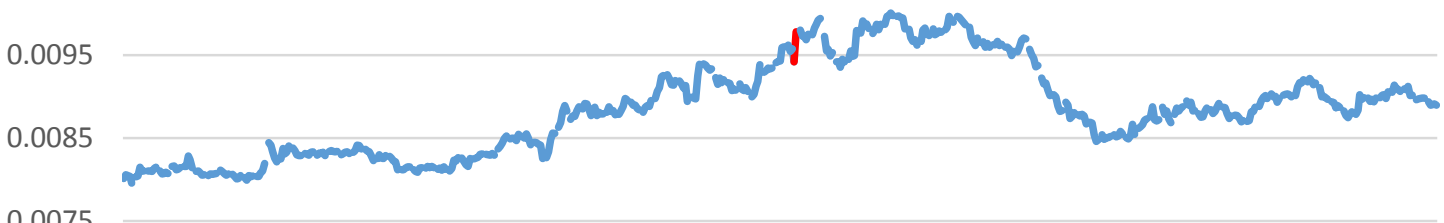

0.0075

\section{Gold}

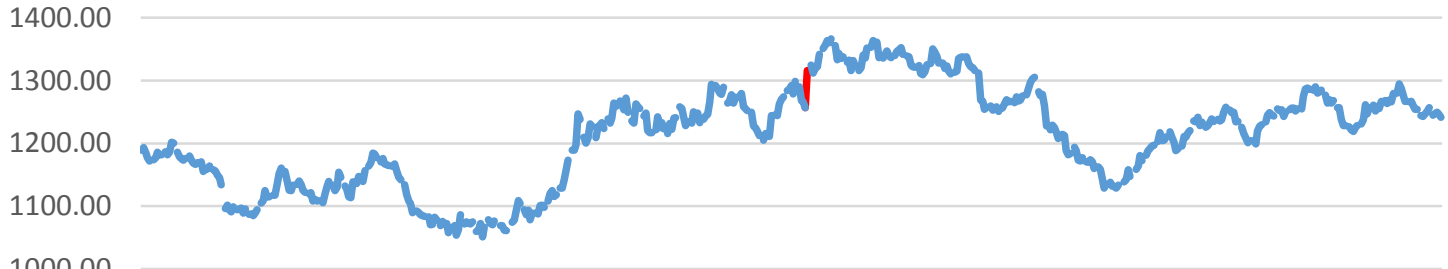


Figure 2. Correlation among currencies. This figure shows the correlation coefficients over time among the five currencies before and after the Brexit vote. The correlation is based on the Dynamic Conditional Correlation model of Engle (2002) and its improvement by Aielli (2013). The vote corresponds to the spikes in the middle area of the gra

GBP - EUR

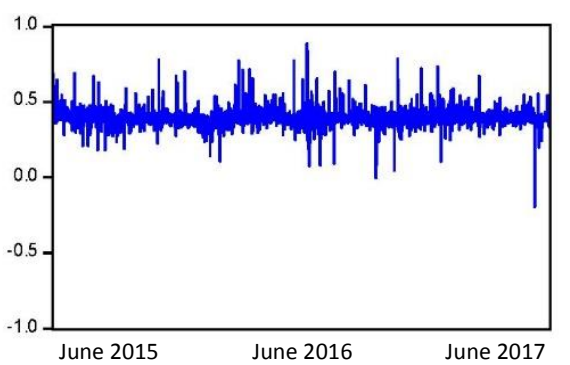

EUR - CHF

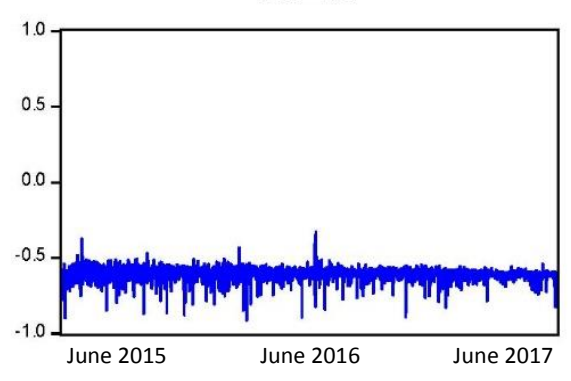

CHF - Gold

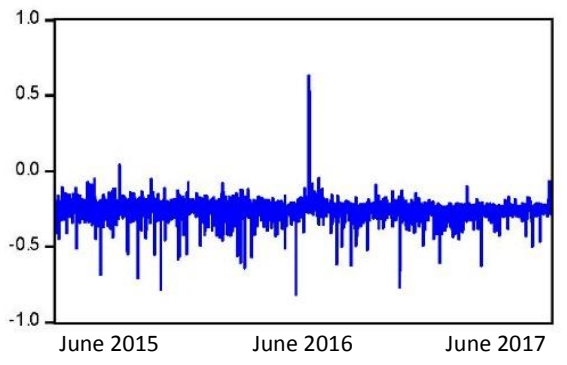

GBP - CHF

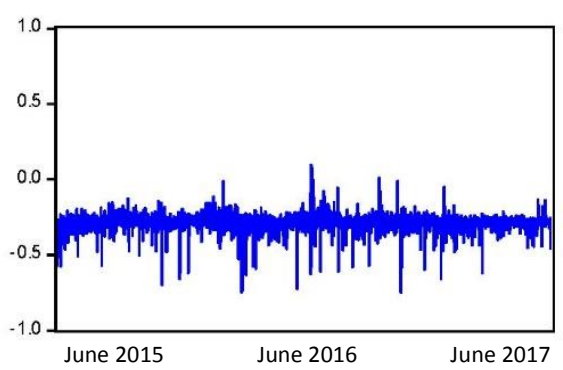

EUR - JPY

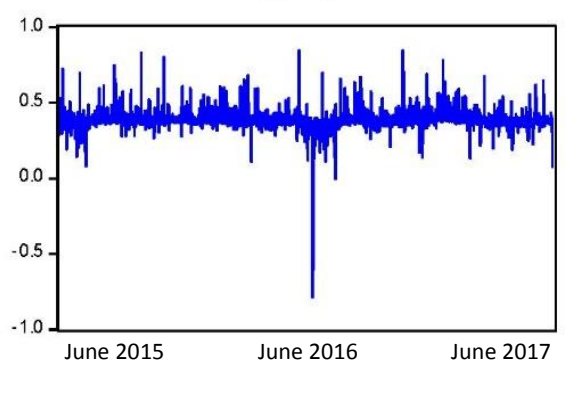

JPY - Gold

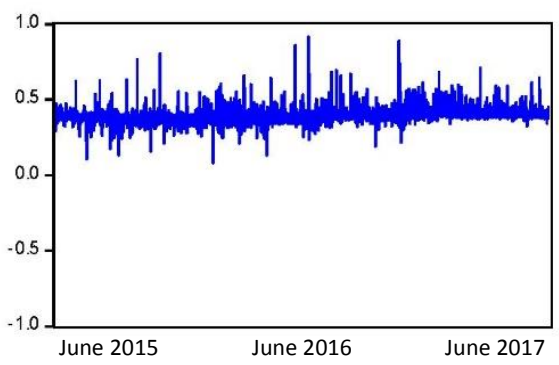

GBP - JPY

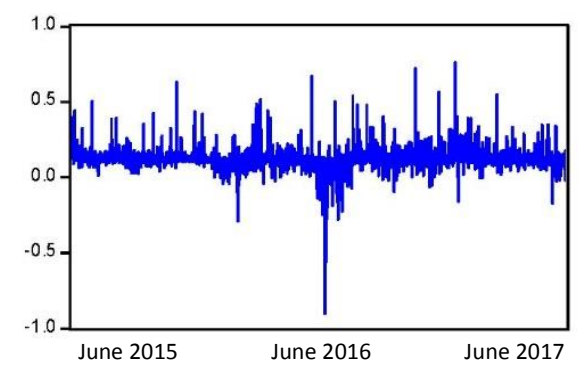

EUR - Gold

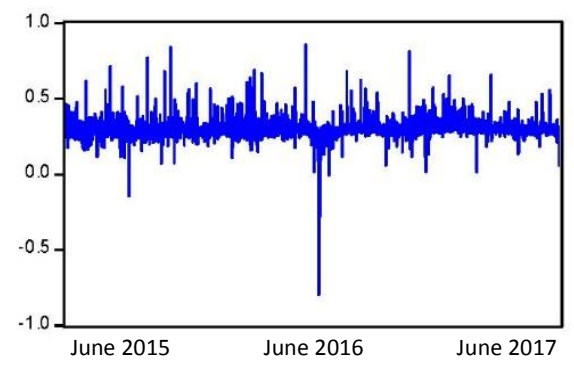

GBP - Gold

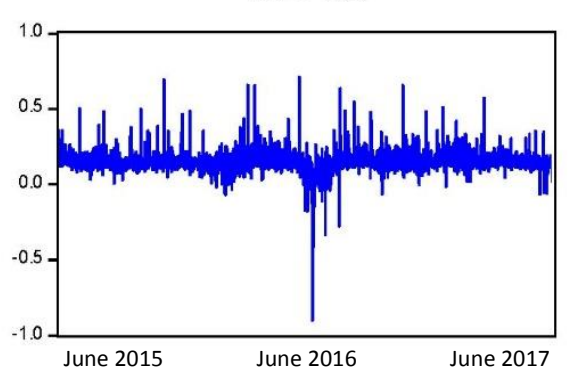

CHF - JPY

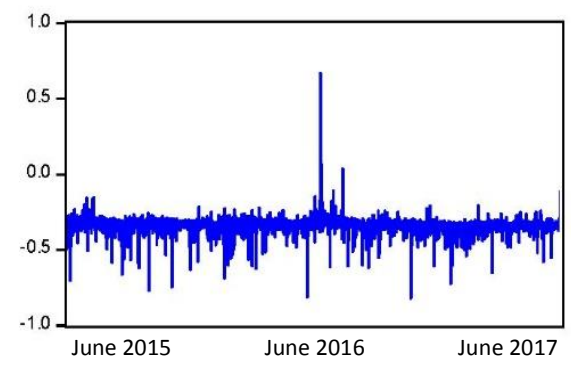


